\title{
DIALÉTICA SINGULAR-PARTICULAR-UNIVERSAL E SUA EXPRESSÃO NA PEDAGOGIA HISTÓRICO-CRÍTICA: PRIMEIRAS APROXIMAÇÕES
}

\author{
Juliana Campregher Pasqualini ${ }^{1}$
}

\begin{abstract}
Resumo
Tecem-se primeiras aproximações entre a dialética singular-particular-universal e a teoria pedagógica histórico-crítica, com base em uma exposição das categorias de singularidade, universalidade e particularidade articuladas às exigências que o método materialista histórico-dialético coloca como condição para conhecer a realidade em sua concretude. Argumenta-se que a pedagogia histórico-crítica carrega em sua formulação o movimento destas categorias, formulando-se apontamentos relativos ao conceito de trabalho educativo, ao problema do currículo e ao sujeito-destinatário do ato pedagógico, buscando evidenciar que as categorias de singular, particular e universal possibilitam múltiplos movimentos analíticos no campo da educação escolar.
\end{abstract}

Palavras-chave: pedagogia histórico-crítica; dialética singular-particular-universal; produção de conhecimento; trabalho educativo.

\section{Introdução}

O tema que me foi proposto para exposição nesse Simpósio ${ }^{2}$ é complexo e desafiador, razão pela qual solicitei à comissão organizadora a inclusão do subtítulo: primeiras aproximações. Pensar as relações entre a pedagogia histórico-crítica e a dialética singular-particular-universal nos convoca, de partida, a refletir sobre o processo de produção de conhecimento, ou seja, sobre a possibilidade de conhecer a realidade e os caminhos que permitem efetivar essa possibilidade. Singularidade, particularidade e universidade são categorias importantes no processo de conhecer o mundo, conhecer a realidade social e natural que nos rodeia. A teoria pedagógica, por sua vez, necessita enfrentar a questão da formação, no estudante, da relação consciente com a realidade, que pressupõe a apropriação de conhecimento capaz de desvelar e revelar os nexos dinâmicocausais dos fenômenos e objetos da realidade.

Voltando-se à expressão da dialética singular-particular-universal na teoria pedagógica em

\footnotetext{
${ }^{1}$ Docente do Departamento de Psicologia da UNESP/Bauru e do Programa de Pós-Graduação em Educação Escolar da UNESP/Araraquara.

${ }^{2}$ Este artigo registra minha participação no I Simpósio Materialismo Histórico-Dialético e Educação Ambiental, organizado pelo Grupo de Pesquisa em Educação Ambiental. Trata-se de manuscrito elaborado a partir da transcrição da fala realizada nessa ocasião, submetida à revisão visando a incorporar aspectos importantes para a compreensão do objeto de discussão e que porventura foram pouco desenvolvidos na exposição oral. Agradeço ao professor Tiago Nicola Lavoura pela leitura e comentários do texto nesta etapa.
} 
questão, planejo me deter, no primeiro momento de minha exposição, nas categorias de singularidade, universalidade e particularidade. Principiaremos, portanto, por um momento mais abstrato, e também mais denso. Para esse primeiro movimento apoiar-me-ei em um estudo realizado em parceria com a professora Lígia Márcia Martins e publicado na forma de artigo intitulado "Dialética singular-particular-universal: implicações do método materialista dialético para a psicologia" (PASQUALINI; MARTINS, 2015). No segundo momento do percurso expositivo, pretendo compartilhar algumas ideias, ou ensaios, referentes à expressão da dialética singular-particular-universal na pedagogia histórico-crítica, destacando a importância do movimento destas categorias para pensarmos a Educação sob enfoque histórico-crítico.

\section{A Unidade Contraditória Singular-Universal e a Particularidade Como Mediação}

Entendo que abordar as categorias singular, particular e universal é uma tarefa que, como já indiquei, tem relação com o problema de conhecer a realidade, e, portanto, necessita ser enfrentada dentro dos marcos do método materialista histórico-dialético em sentido amplo. O que quero enfatizar é que não podemos focalizar a dialética singular-universal sem recorrer ao sistema categorial do método como um todo: a análise destas categorias deve se dar dentro de uma compreensão mais ampla sobre o método que nos orienta no esforço de conhecer, concretamente, a realidade.

O materialismo histórico-dialético concebe o conhecimento como um processo de captação e reprodução, no pensamento, do movimento do real, proposição essa que o diferencia de outros métodos, de outras concepções, de outras epistemologias. Partimos de uma concepção que afirma a primazia ontológica do real: conhecer o real é um esforço que realizamos para reconstituir, no nosso pensamento, o movimento da realidade, um esforço de captar, desvelar, decodificar como é que a realidade concretamente se faz. O que são os fenômenos da realidade e como "funcionam"? Isso é conhecimento! Esta concepção de conhecimento é ponto de partida para entender as categorias que nos interessam mais diretamente nesta exposição.

O método nos ensina que existem algumas condições para que consigamos, de fato, captar e reconstituir o movimento do real no pensamento. Necessitamos, nesse processo, orientar o nosso pensamento por algumas categorias, com destaque a três principais: movimento (ou processualidade), contradição e totalidade. A realidade está em permanente movimento. Podemos 
dizer que o real é movimento, e dessa condição ontológica se desdobra a exigência epistemológica de que o pensamento humano seja capaz de captar esse movimento, captar os fenômenos em sua processualidade. Este já é um primeiro desafio, pois em nossa sociedade o pensamento tem como tendência dominante "congelar" a realidade, pressupondo que os fenômenos são estáticos, naturais, eternos, sempre iguais a si mesmos. Apreender os fenômenos em sua processualidade é uma primeira condição para conhecer o real, porque é ela que nos revela a gênese e o processo formativo daquilo que nos propomos a investigar, ou seja, a historicidade do fenômeno em questão e suas tendências de futuro desenvolvimento.

A segunda condição é entender que a realidade é permeada por contradições, e que a contradição não é um desvio, uma anomalia, mas o próprio motor do movimento dos fenômenos. Em outras palavras, a contradição é inerente aos fenômenos da realidade. O que isso significa? Que os fenômenos se constituem de forças opostas, tendências opostas, contrárias, que coexistem em unidade. Trata-se também de uma diretriz deveras desafiadora, pois nosso pensamento é "treinado" para enxergar a identidade: isto ou aquilo, se é isto não é aquilo. A dialética materialista nos permite perceber que é substituir este ou por $e$ : é isso e é aquilo ao mesmo tempo. Isso é trabalhar com contradição, ou pensar por contradição. A esse respeito, vale alertar que contradição não se confunde com incoerência, ou contrassenso, mas diz respeito à necessidade de se decodificar quais são as tendências e contra-tendências que, em sua luta, engendram o movimento dos fenômenos.

A terceira condição para apreensão do real em sua concretude é que nosso pensamento se oriente pela categoria de totalidade. Não se deve entender, evidentemente, que para se conhecer a realidade seja preciso apreender tudo. Totalidade não é tudo. Totalidade é conseguir captar as interconexões fundamentais entre os fenômenos. Os fenômenos e objetos da realidade estão interligados, estão interconectados entre si, compõem e integram uma mesma totalidade, um mesmo sistema de mediações e múltiplas relações. Coisas que parecem independentes uma da outra podem se revelar, mediante exame atento e rigoroso pelo pensamento, relacionadas entre si, elementos de uma mesma totalidade, desdobramentos de uma mesma relação essencial em conexão de dependência e/ou determinação. Dessa forma, apreender um fenômeno considerando sua totalidade significa apreender o sistema de mediações e determinações a que ele se integra, desvelando suas relações internas mais essenciais, ou seja, as relações que o engendram e o sustentam.

As orientações mais gerais do método materialista histórico dialético são essas: que 
tenhamos um olhar de totalidade, que consigamos pensar por contradição, que busquemos aprender os fenômenos em sua processualidade.

Uma vez que o método coloca essas categorias, vai ficando evidente que a forma pela qual os fenômenos se apresentam a nós oculta muito do que eles de fato são, afinal, é necessário um esforço consciente do pensamento para alcançar a perspectiva de totalidade em relação a dada problemática, para apreender seu movimento, para identificar contra-tendências. A captação imediata não garante, ou por vezes obstaculiza, a apreensão destas dimensões. Por essa razão o método vem nos dizer que para conhecer a realidade é necessário superar a aparência fenomênica, isto é, superar a forma de aparecer do fenômeno. Na terminologia de Karel Kosik (1976), que em minha trajetória pessoal foi um dos autores mais importantes no estudo do método, precisamos superar a pseudoconcreticidade à vista de apreender as determinações dinâmico-causais essenciais dos fenômenos.

A forma de aparecer do fenômeno revela algumas coisas e oculta outras, de modo que se faz necessário superar a aparência imediata inicial, caso contrário nos manteremos reféns do observável, da empiria, daquilo que se mostra à primeira vista, o que significaria determo-nos no pseudoconcreto, impedidos de captar as relações internas essenciais do fenômeno em questão. O quê, de fato, está produzindo dado fenômeno, fazendo com que tenha a forma que tem, seja do jeito que é? O que é essencial na causalidade deste fenômeno? E o que é secundário, acessório, acidental? Ou ainda, o que é essencial e o que secundário para explicar este fenômeno? Na forma de aparecer, por vezes aquilo que é secundário está em destaque; na ausência de análise, corremos o risco de não perceber que o que de fato importa está, por assim dizer, escondido, e o que salta aos olhos é, em verdade, secundário.

É no interior dessa concepção de realidade e de conhecimento, ou como parte dela, que se situa, no campo do marxismo, a discussão sobre singular, particular e universal. Lukács é um dos autores que propõe que uma autêntica e verdadeira aproximação e compreensão da realidade pressupõe a explicitação dos nexos entre as dimensões singular, particular e universal dos fenômenos - categorias que já se fazem presentes na filosofia anteriormente à própria formulação marxiana, mas que, na lavra de Marx, conquistam historicidade e concretude (LAVOURA, 2018). Lukács nos indica que, como parte do esforço de captar movimento, contradição e totalidade e alcançar as determinações essenciais dos fenômenos, impõe-se uma tarefa importante que é identificar o que é singular, particular e o que é geral ou universal no fenômeno. Podemos entender 
que se trata de mais uma ferramenta para o pensamento em seu desafio de apreensão do real.

De partida é importante que esteja claro que singular, particular e universal não são pontos de vista sobre o fenômeno. Trata-se de um entendimento decisivo. Não nos referimos ao "ponto de vista" da singularidade, ou da universalidade. Não é disso que se trata! Não falamos em perspectivas. Lukács postula que a dialética singular-particular-universal é uma propriedade objetiva dos fenômenos. São dimensões que coexistem no fenômeno, cuja captação perseguimos pela via do pensamento. Realizamos um esforço para apreender, identificar essas dimensões, decodificar como estão conectadas, inter-relacionadas, de que modo se tensionam e se codeterminam. Também é decisivo que fique claro que todo objeto, todo fenômeno é ao mesmo tempo singular, particular e universal, e, portanto, não se trata de identificar aquilo que é singular, aquilo que é universal, como se uma coisa fosse singular, outra particular, outra universal. É no mesmo fenômeno que decodificaremos o singular, o particular e o universal coexistindo.

Passemos agora a olhar para cada um desses conceitos, começando pela singularidade - que é, afinal, sempre nosso ponto de partida. Lukács (1978) dirá que quando entramos em contato com o fenômeno empírico, trata-se de uma ocorrência singular. Os fenômenos com que nos enfrentamos são sempre singulares, são sempre únicos e irrepetíveis. O fenômeno nunca é absolutamente idêntico a outro, haverá sempre uma dimensão singular. Trazendo isso para o campo da educação, podemos afirmar que cada aluno é um ser singular, nunca haverá um estudante exatamente igual, idêntico a outro. Cada aluno é um aluno singular, assim como cada professor, pois a individualidade é única, irrepetível e, portanto, singular. De modo imediato, diz Lukács, não nos enfrentamos senão com a singularidade. Nas palavras do autor: "tudo o que nos oferece o mundo externo como certeza sensível, é imediatamente e sempre algo singular ou uma conexão única de singularidades. É sempre isto singular, um aqui e agora singular" (LUKÁCS, 1967, p. 203). A singularidade referese às definibilidades irrepetíveis do fenômeno em sua manifestação imediata, acessível à contemplação viva.

Se o singular é aquilo com que nos deparamos no imediato, e já afirmamos que a empiria é insuficiente para a captação do real em sua concretude, podemos compreender que a singularidade, em si mesma, encontra-se ainda no plano da aparência do fenômeno. Vejamos. Em que pese a irrepetibilidade que caracteriza a individualidade do estudante, ao longo dos anos, acumulando experiência na docência, vamos perceber que existem regularidades. Há sempre aquele aluno mais quieto, aquele mais arteiro, um mais amoroso, outro que é mais arredio... É como se alguns "tipos" 
se repetissem nas várias turmas. À medida que acumulamos uma certa experiência com diversas e variadas singularidades vamos identificando traços que se repetem, que são regularidades. Não se trata de um fenômeno do acaso. Isso tem uma razão de ser. Por que será que algumas coisas se repetem? Por que algumas coisas são típicas? Será a individualidade tão-somente singular? A dialética singular-particular-universal ilumina esta questão.

Para avançar neste percurso passarei a tratar do polo universal dessa dialética. Vimos que superar a aparência singular do fenômeno implica revelar as relações dinâmico-causais a ele subjacente, ocultas à contemplação imediata. É preciso captar as múltiplas mediações que o determinam e o constituem. Isso requer que sejamos capazes de apreender as leis gerais que determinam e regulam a existência do fenômeno no mundo objetivo.

Observem que estamos afirmando a existência de leis gerais que regulam a existência dos fenômenos. Trata-se de uma propriedade do real. Não se trata de interpretação, de simbolização, de algo criado pelo psiquismo humano, mas de uma propriedade objetiva dos fenômenos da realidade que o pensamento humano esforça-se por apreender e decodificar. A realidade é marcada por regularidades, o modo de existir dos fenômenos se tece como desdobramento de relações gerais, regidos por elas. Descobrir quais sejam essas leis é condição para conhecer concretamente a realidade em seu movimento contraditório.

Do exposto podemos concluir que todo fenômeno singular contém em si determinações gerais, universais. Eu dizia, de início, que todo fenômeno é singular-particular-universal ao mesmo tempo. Nosso percurso aqui começou pelo reconhecimento da singularidade, do irrepetível, do único, e agora o que se coloca em destaque é a necessidade de se perceber que esse irrepetível é singular, mas não é apenas ou meramente singular. O singular contém determinações gerais, universais, que valem para todos os fenômenos daquele "tipo". Para produzir conhecimento sobre o fenômeno, é necessário alcançar quais são as leis gerais que o explicam, e retornar ao próprio fenômeno de modo a decodificar esse trânsito de singularização de propriedades universais e universalização de traços singulares.

No já mencionado artigo escrito em parceria com Lígia (PASQUALINI; MARTINS, 2015), utilizamos como exemplo, para pensar o que são as leis gerais, a anedota segundo a qual Isaac Newton descobriu a lei da gravidade observando a queda de uma maçã. Uma maçã que cai é uma ocorrência singular: aquela maçã, aquela queda, aquele momento. Nunca haverá uma maçã 
absolutamente idêntica a outra e nunca mais se repetirá aquele momento, naquela circunstância. Mas... por que a maçã caiu? Aquela maçã caiu naquela circunstância porque existe um fenômeno chamado gravidade. A lei da gravidade não se apresenta, em si mesma, à contemplação viva, mas ela está ali, determinando a forma de existir daquele fenômeno, embora permaneça em certo sentido oculta aos sentidos humanos. A gravidade é uma lei geral que explica a queda de todas as maçãs portanto, desse conjunto de ocorrências singulares assemelhadas. Mas o movimento analítico vai muito além. A lei da gravidade explica a queda de qualquer objeto no planeta Terra, e ainda vários outros fenômenos, como a órbita da Lua em torno da Terra: fenômenos diversos têm a lei da gravidade como determinação essencial.

Produzir conhecimento pressupõe, assim, que sejamos capazes de, ao observar a singularidade, desvendar a relação geral que a produz e sustenta. Vale observar que, para efetivamente retratarmos esse movimento analítico, a categoria do particular se impõe como necessária, como buscarei argumentar logo a seguir, pois o que vemos ao nos debruçarmos sobre a relação entre ocorrências singulares e relações gerais é que uma mesma relação geral se particulariza, se concretiza em formações particulares muito diversas - seja a queda dos corpos, seja a órbita dos corpos celestes.

Antes de focalizamos a categoria de particular, me parece fundamental pontuar, a respeito da dimensão universal ou geral dos fenômenos, que quando trazemos essa problemática para o campo das Ciências Humanas somos levados a um outro nível de complexidade. Isto porque as leis gerais que regem os fenômenos humanos serão leis históricas, leis que se transformam com o próprio processo histórico. É importante tomar isso em conta para que não se incorra no erro de procurar uma essência platônica, eterna, imutável dos fenômenos humanos: quando o método se refere a aparência e essência, deve-se compreender que se trata da referência a traços essenciais, determinações nucleares de natureza histórica e concreta. Parece-me importante pontuar isso, pois a palavra essência vem carregada de outras significações, podendo induzir a uma compreensão equivocada do processo de produção de conhecimento.

Para apreender as leis gerais é preciso suspender ou abstrair momentaneamente as formas fenomênicas singulares. Marx nos ensinou que precisamos chegar às abstrações: as mais simples. O que significa esta orientação? O que prevê o momento da abstração no processo de produção do conhecimento? Abstração é suspender temporariamente as diferenças, diversidades, singularidades, procurando apreender o que é que conecta formações singulares diversas. A tarefa 
do pesquisador, portanto, é desvelar como a universalidade se expressa na singularidade, como ela se concretiza em cada singularidade, naquela singularidade. Mais que isso: como a universalidade se expressa e se concretiza na diversidade de expressões singulares do fenômeno. Na queda da maçã ou na órbita da Lua. Recuperando o problema da individualidade, devemos entender, como aprendi com o professor José Luis de Almeida quando fui sua aluna no curso de Mestrado, que o ser humano é ao mesmo tempo portador de uma singularidade que o distingue de todos os outros seres e de uma generalidade, que o torna semelhante a qualquer outro, ao mesmo tempo. Algo aparenta não guardar nenhuma relação com outro algo, mas a investigação revelará que ambos estão profundamente interconectados, integrando uma mesma totalidade. Trata-se de uma diretriz para a pesquisa científica, mas também uma orientação importante para a peleja da vida, para enfrentar os desafios diários da existência.

Lukács afirma que o caminho do pensamento e do conhecimento é uma ininterrupta oscilação para cima e para baixo, da singularidade à universalidade e desta àquela. E é assim que produzimos conhecimento, enfrentando a tensão dialética entre singular e universal. O singular nega o universal ao mesmo tempo que o realiza, e da mesma forma o universal nega o singular ao mesmo tempo que o contém. Deparamo-nos com a singularidade, detemo-nos sobre ela, investigando, examinando, abstraímos o plano fenomênico buscando leis gerais/universais que ali se expressam e se particularizam, detemo-nos sobre as relações gerais, e voltamos a olhar para a singularidade em busca de compreender o modo de expressão singular dessas relações gerais. Nesse complexo movimento é que vamos entendendo porque aquele fenômeno é como é. O movimento entre os polos é o fundamental.

Outro apontamento relevante é que o significado de universal, no materialismo histórico dialético, não corresponde às características comuns a dados objetos e fenômenos, a se detectar o que há de comum entre uma coisa e outra. Um autor que faz uma discussão muito clara a esse respeito é o filósofo Evald Ilyenkov, leitura que recomendo a quem pretende aprofundar o entendimento da dialética materialista. Ilyenkov (2008) explica que o pensamento orientado pela lógica formal persegue a classificação, e para classificar os fenômenos busca semelhanças em suas características; já quando esposamos a dialética, devemos compreender que os traços essenciais pertencem ao plano interior, ao plano genotípico e não fenotípico dos objetos. Com Karel Kosik podemos compreender que as características situam-se no plano da aparência pseudoconcreta, e que, portanto, estas revelam e ao mesmo tempo ocultam as determinações essenciais do fenômeno. 
Vamos nos deter um instante nesta proposição. Estou me referindo ao seguinte: muitas vezes dois objetos que compartilham a mesma característica não constituem expressões de uma mesma universalidade, de uma mesma relação geral. Da mesma forma, dois objetos ou fenômenos que parecem muito diferentes por suas características fenomênicas estão, em verdade, conectados a um mesmo todo, integram um mesmo sistema de mediações e determinações, desdobram-se de uma mesma determinação essencial. Isto porque uma mesma relação geral pode se expressar de formas muito diferentes - particulares - na realidade. A diretriz do método é, então, que não se deve buscar o universal nas meras similaridades entre um e outro fenômeno. A febre é um exemplo interessante para ilustrar essa defesa: ela é um sintoma comum a inúmeras doenças que acometem o organismo; o xis da questão é identificar a causalidade do sintoma, chegando ao diagnóstico. Eventualmente, podemos em dado momento ter um paciente febril e outro sem febre que padeçam da mesma patologia. Trazendo este princípio para o chão da sala de aula, podemos, por exemplo, considerar que o comportamento agressivo ou hostil de diferentes alunos para com a professora ou colegas pode ter causações dinâmicas diversas, embora manifestem-se de forma aparentemente semelhante. Um comportamento aparentado a outro não nos permite concluir que ambos resultam ou estão sendo engendrados pelos mesmos processos sociais. É preciso analisar metodicamente o fenômeno singular e buscar identificar, naquela específica história de vida, naquele específico contexto social, naquele específico sistema de interações, o que está produzindo o comportamento em questão, decodificando-se o sistema de mediações e determinações que subjazem. Em sentido semelhante, devemos considerar que comportamentos muito diferentes em aparência podem ser, em essência, expressões de uma mesma lógica de relação social. Pensemos, por exemplo, na hostilidade e na apatia: ambas podem instituir-se como expressão do sem-sentido, da alienação da atividade social e da própria condição humana. A análise deve, nesse caso, revelar a necessidade que determina o desenvolvimento das multiformes manifestações do fenômeno ${ }^{3}$.

Vimos, em suma, que singular e universal são dimensões que coexistem no fenômeno, se articulam e se determinam reciprocamente. São os polos opostos da unidade dialética que dá vida ao fenômeno. Como postos, singular e universal se identificam à mesma medida que se

\footnotetext{
${ }^{3}$ Ilyenkov (2008) operas um exercício de análise do movimento entre singular e universal tomando como objeto a atividade vital humana, o trabalho. Trabalho é o intercâmbio entre ser humano e natureza em que o ser humano por sua atividade, transforma a natureza buscandso a satisfação de suas necessidades, e nesse processo transforma a si mesmo. Podemos dizer que essa é uma definição universal de trabalho, que retrata sua generalidade, seu traço mais essencial, e que se concretizartá e se expressará de formas diversas nas ocorrências singulares de tal atividade inclusive na experiência de alienação do trabalho.
} 
contrapõem, e nessa tensão opera como mediação a particularidade: a contínua tensão entre singular e universal manifesta-se na configuração particular do fenômeno. A particularidade expressa a universalidade e condiciona o modo de ser da singularidade. A singularidade se constitui sob determinadas condições, de modo específico, não completo, não universal; as condições nas quais o fenômeno ocorre serão decisivas para sua forma de existir, para sua forma de manifestação, isto é, a forma pela qual aquela universalidade irá se particularizar, se especificar na ocorrência singular do fenômeno.

Em “Introdução a uma estética marxista”, Lukács (1978) atribui à particularidade o caráter de mediação entre o singular e o universal, asseverando que ela nos permite superar a singularidade imediata ou isolada, à medida que “(...) revela na existência única e irrepetível dos indivíduos e fenômenos uma expressão particular da universalidade. Com isso, a singularidade é reencontrada em sua rica determinação pelos atributos da universalidade." (PASQUALINI; MARTINS, 2015, p. 368).

Pensemos em um trabalhador de fábrica, um metalúrgico da região do $\mathrm{ABC}$ Paulista. Este homem trabalha. O trabalho é uma condição universal do ser humano. Mas a atividade do nosso trabalhador se realiza sob dada condição particular: trata-se de um trabalhador de fábrica em uma sociedade capitalista. Seu modo singular de vivenciar o trabalho está condicionado por essa particularidade, o trabalho fabril, marcado por traços bastante específicos perante outras formas de labor no interior da mesma sociedade capitalista, seja o trabalho rural, o trabalho educativo, o trabalho no setor de transportes ou de serviços. Se olharmos para o conjunto dos trabalhadores metalúrgicos em exercício hoje, notaremos que a localização geográfica do $\mathrm{ABC}$ e sua configuração histórica e sócio-política impõe circunstâncias muito diferentes daquelas a que estão submetidos empregados de plantas fabris instaladas no Nordeste do país. Se considerarmos a divisão internacional do trabalho, constataremos que suas condições diferem enormemente das de colegas operários da Alemanha. Estas são condições particulares que especificam a atividade de trabalho, e acabam por conferir a ela propriedades específicas, o que significa dizer que a totalidade social se sustenta em formas específicas de organizar o trabalho, às quais as pessoas vão se vincular desde sua condição singular.

Seguindo ainda neste exercício analítico, também podemos considerar que a singular experiência como trabalhador do nosso personagem é potencialmente diversa de mulheres metalúrgicas, por serem bastante demarcadas as relações de gênero em nossa sociedade, permeadas 
que são por profundas desigualdades, opressões e violência. É também fundamental nos indagarmos sobre a condição étnico-racial deste trabalhador, ou destas trabalhadoras. Periferia ou centro, vínculo empregatício, subemprego ou informalidade, contexto urbano ou rural: são diversas as delimitações que se impõem e condicionam o modo de ser da singularidade, e o movimento de sua apreensão é complexo, por vezes tortuoso, exigindo inúmeras “idas e vindas", sendo construído por aproximações sucessivas ${ }^{4}$

Conforme Lavoura (2018, p.9), apoiado em Lukács, a categoria da particularidade constituise “(...) como mediação que explica os mecanismos que interferem no modo de ser da singularidade e da universalidade, ou seja, a particularidade se coloca como mediação que carrega determinações ao singular e ao universal.” Nessa esteira, o método nos ensina que a compreensão da singularidade é tão mais objetiva quanto mais se captem suas mediações particulares com a universalidade. No âmbito da psicologia tal diretriz se faz sumamente relevante. Quando nos debruçamos, por exemplo, sobre a personalidade de uma pessoa, é decisivo que não nos detenhamos na singularidade, que sejamos capazes de apreender a universidade que se particulariza nessa personalidade, as generalidades que nela se especificam. Eu disse, de início, que não existe um aluno igual a outro, pois a singularidade é única e irrepetível. Este é um fato. Não obstante, como também já colocado aqui, toda e cada singularidade é portadora de generalidades que a conectam e assemelham a todas as outras singularidades. Devemos considerar, entre outros aspectos, o modo de produção capitalista e seu atual estágio de desenvolvimento (ou degeneração) como condição que é partilhada pela esmagadora maioria dos seres humanos viventes hoje, e que representa determinação decisiva no processo de personalização. Na tensão entre singular e geral serão engendradas configurações particulares de personalidade, entendida aqui como processualidade que vai sofrendo essas determinações gerais e particulares da totalidade social.

Em síntese, o percurso até aqui trouxe as seguintes proposições: i) a expressão singular do fenômeno é irrepetível e revela sua imediaticidade e definibilidade específicas, mas carrega, em seu interior, determinações gerais que se particularizam; ii) em sua expressão ou dimensão universal, se revelam as conexões internas e as leis gerais do movimento e processo formativo do

\footnotetext{
${ }^{4}$ Aqui me parece importante esclarecer que os polos singular e universal/geral não são fixos, mas referidos ao próprio objeto de investigação e análisde. Poderíamos, a título de ilustração, nos debruçarmos sobte as desigualdades internas à categoria mulher em nossa sociedade; nesse caso, tomaríamos o gênro feminino como polo geral, e ao perscrutar sua múltiplas e diversas expressões singulares, detectaríamos as inter-relações com a consição de classe, raça/enia, deficiência, orientação sexual, como centrais para apreender o feminismo em sua concretude.
} 
fenômeno; iii) a universalidade se materializa na expressão singular do fenômeno pela mediação da particularidade, razão pela qual afirmamos que o particular condiciona o modo de ser do singular e especifica (particulariza) o universal.

\section{Pensar o Trabalho Pedagógico à Luz da Dialética Singular-Particular-Universal}

Como o movimento lógico-metodológico sobre o qual me debrucei até aqui se expressa na pedagogia histórico-crítica? O que pretendo argumentar é que esta teoria pedagógica carrega em seu interior a dialética singular-particular-universal, isto é, que tais categorias compõem a dinâmica interna da pedagogia histórico-crítica e de seu método, pelo simples fato de tomar como fundamento teórico-metodológico o materialismo histórico-dialético. Alguns trabalhos começam a se ocupar justamente de explicitar os nexos entre a dialética singular-particular-universal e a pedagogia histórico-crítica, com destaque a Lavoura (2018, p. 4). O autor alerta que

a não apreensão da dialética do singular, do universal e do particular - categorias fundamentais do método em Marx - no âmbito dos fundamentos da pedagogia histórico-crítica pode conduzir ao desenvolvimento do trabalho pedagógico que se pretende orientado por esta teoria com inúmeros problemas de ordem teóricoprática.

Passo então a sinalizar possíveis implicações desta premissa lógico-metodológica para pensarmos o fenômeno da educação em uma perspectiva crítica e historicizadora, indicando, de partida, que seria equivocado buscar identificar quais questões ou quais aspectos da teoria pedagógica histórico-crítica são afetadas ou marcadas pela dialética singular-particular-universal: é fundamental que se compreenda que a tensão dialética entre singular e universal em que o particular insurge como mediação configura uma elaboração conceitual referida ao próprio modo de constituir-se a realidade, no que se inclui o fenômeno da educação. Trata-se de uma concepção geral, um entendimento sobre o modo de ser dos fenômenos da realidade. Por essa razão, toda proposição realizada pela pedagogia histórico-crítica, sendo esta uma teoria de fundamento marxiano, se fará marcada por esta dialética. Trata-se de um princípio que devemos convocar para pensar os variados objetos e problemas particulares de que se ocupa a teoria pedagógica. Nesta oportunidade quero trazer apontamentos relativos ao conceito de trabalho educativo, ao problema do currículo e ao sujeito-destinatário do ato pedagógico, buscando evidenciar que as categorias de singular, particular e universal possibilitam múltiplos movimentos analíticos a depender daquilo 
que se demarca como objeto.

O conceito de trabalho educativo proposto pela pedagogia histórico-crítica o concebe como ato de produção da humanidade em cada indivíduo, deve ser entendido como uma formulação geral, universal, e nesse sentido abstrata. O trabalho educativo de caráter escolar pode ser considerado uma especificação deste ato, que lhe traz certas condições e configurações, donde o ensino escolar que se realiza em cada unidade escolar será expressão singular desse fenômeno histórico-social, carregando traços universais ali particularizados. Da mesma forma que o trabalho como atividade vital humana (universal) pode concretizar-se como trabalho alienado (ILYENKOV, 2008), cabe refletir sobre o conteúdo particular que assume a produção da humanidade nos diversos e múltiplos contextos singulares em que se realiza o ato educativo. A pedagogia histórico-crítica se propõe, justamente, a elaborar ferramentas teórico-práticas que colaborem para que o trabalho educativo seja capaz de reconstituir, nos estudantes, as máximas realizações culturais da humanidade, superando particularismos e contrapondo-se à tendência dominante, na sociedade capitalista e particularmente brasileira, de reproduzir o humano assujeitado.

Importa, pois, refletir sobre os projetos curriculares que realizam a intencionalidade pedagógica de reconstituir no pensamento do estudante singular os sistemas conceituais elaborados pela humanidade ao longo da história e acumulados como patrimônio universal. Lavoura (2018, p. 12) defende, nesse sentido, que "o conceito de educação como mediação em Saviani é a expressão da particularidade da relação entre indivíduo singular e gênero universal humano", posto caber ao trabalho educativo "a função de possibilitar aos indivíduos a apropriação dos conhecimentos mais desenvolvidos na história da humanidade relativos às ciências, às artes e à filosofia." Ainda segundo o autor, a construção singular, de cada indivíduo, dependerá de mediações particulares que possibilitem a apropriação e a objetivação do vir-a-ser humano condensado na universalidade do gênero, destacando-se justamente a mediação do ensino escolar, pelos movimentos de problematização e instrumentalização.

Nestes termos é que podemos refletir sobre a relação que o sujeito-destinatário do ato pedagógico trava com os conteúdos escolares no processo de ensino. Recorrendo a Saviani (2012), temos que é preciso, em primeiro lugar, que sejamos capazes de perceber nosso aluno como indivíduo concreto, superando o aluno empírico.

À vista das características da subjetividade humana, evidenciadas pela perspectiva 
marxiana, o educador, o professor, defronta-se com um educando, com um aluno concreto, e não simplesmente com um aluno empírico. Isto significa que o aluno, isto é, o indivíduo que lhe cabe educar, sintetiza em si as relações sociais próprias da sociedade em que vive e em que se dá o processo de sua educação. (p. 42, grifo nosso)

Tal superação da empiria fenomênica do "ser aluno" requer que o sujeito-destinatário que se nos apresenta em sua singularidade possa ser apreendido para além do que a percepção imediata comunica, identificando-se nele o movimento de determinações gerais que se particularizam, ao mesmo tempo negando e afirmando o singular. A título de ilustração, Saviani (2012) considera o caso em que o aluno mostra-se desinteressado em sua singularidade aparente: cabe ao professor ultrapassar esta pseudoconcreticidade e apreender o interesse inerente a sua condição de classe: aos filhos da classe trabalhadora, ao nível histórico-social, interessa o conhecimento, o que nos impõe a necessidade de decodificar o sistema de determinações e mediações subjacente à tensão interessedesinteresse pelo conhecimento:

(...) como indivíduo empírico, a criança se interessa por satisfações imediatas ligadas à diversão, à ausência de esforço, às atividades prazerosas. Como indivíduo concreto, por sintetizar as relações sociais que caracterizam a sociedade em que vive, seu interesse coincide com a apropriação das objetivações humanas, isto é, o conjunto dos instrumentos materiais e culturais produzidos pela humanidade e incorporados à forma social de que a criança participa. (SAVIANI, 2012, p. 44)

A mediação pedagógica de orientação histórico-crítica tenciona proporcionar a apropriação, pelo estudante (indivíduo singular), do conjunto dos instrumentos materiais e culturais produzidos pela humanidade a que se refere Saviani, concebidos como conteúdos universais que constituem patrimônio humano-genérico. Ao elaborarmos projetos curriculares, devemos nos orientar por este princípio geral, e ao mesmo tempo ter em conta as condições específicas no interior das quais se processa o trabalho educativo. A incorporação pelos estudantes (singulares) dos nexos conceituais (gerais) sintetizados nos sistemas conceituais das ciências, da arte e da filosofia se dá dentro de um contexto material e simbólico, condicionado por circunstâncias materiais e simbólicas específicas, que devem ser consideradas no processo de ensino. O estudo do agronegócio e suas consequências para a vida social é um conteúdo relevante para todo o alunado brasileiro, mas certamente sua abordagem e significância terá nuances específicas junto a estudantes que habitam cidades que são essencialmente estruturadas em torno da atividade agroindustrial, ou regiões que sofrem mais 
diretamente suas consequências ambientais e sociais. O estudo dos biomas é também um bom exemplo de conteúdo de importância universal que ganha contornos particulares nas diversas regiões geográficas.

Com o exposto, quero enfatizar, ao mesmo tempo, a importância dos conteúdos curriculares que selecionamos orientados pela perspectiva do universal humano-genérico, e a necessidade de contemplar, no planejamento do ensino, o movimento pelo qual as relações gerais se particularizam sob circunstâncias específicas, o que significa destacar, ao lado das questões "a quem se ensina?", “para quê ensinar?”, “o que ensinar?”, “como ensinar?”, o problema das circunstâncias do ensino, pensadas, aqui, em sentido amplo: "sob quais condições se ensina?".

Também é fundamental, por fim, que o planejamento de ensino seja capaz de reconstituir, no pensamento do estudante, o movimento entre as dimensões gerais e particulares dos conceitos estudados, possibilitando-lhes enxergar as ocorrências singulares dos fenômenos das mais variadas ordens nexos dinâmico-causais gerais subjacentes. Tal movimento representa uma requalificação da inserção do estudante na prática social, finalidade última do projeto histórico-crítico.

Com o breve exercício analítico que aqui desenvolvi, espero ter evidenciando a contribuição relevante ou, mais que isso, decisiva, que a compreensão da dialética singular-particular-universal tem para pensarmos as questões educacionais, e particularmente para a edificação de uma teoria pedagógica. Esforços nesta direção vêm sendo realizados destacadamente no campo da didática por Lavoura (2018), e é fundamental que novos trabalhos se somem a esta empreitada, explorando outras dimensões abarcadas pela pedagogia. Nos limites deste texto, apenas sinalizei possibilidades que o movimento das categorias nos proporcionam no sentido da apreensão do real em sua concretude, buscando deixar claro que, a cada problemática específica sobre a qual nos debruçamos, altera-se o conteúdo do que se configura como polo singular e polo universal.

\section{Referências}

ILYENKOV, E. V. The dialectics of the abstract and the concrete in Marx's Capital. Delhi: Aakar Books, 2008.

KOSIK, K. Dialética do concreto. 2. ed. Rio de Janeiro: Paz e Terra, 1976.

LAVOURA, T. N. A dialética do singular-universal-particular e o método da pedagogia histórico-crítica. Nuances: Estudos sobre Educação, Presidente Prudente, v. 29, n. 2, p. 4-18, 2018.

LUKÁCS, G. Estetica I: la peculiaridad de lo estético. Barcelona: Grijalbo, 1967. 
LUKÁCS, G. Introdução a uma estética marxista: sobre a categoría da particularidade. Rio de Janeiro: Civilização Brasileira, 1978.

PASQUALINI, J. C.; MARTINS, L. M. Dialética singular-particular-universal: implicações do método materialista dialético para a psicologia. Psicologia \& Sociedade, Belo Horizonte, v. 27, n. 2, p. 362-371, 2015.

SAVIANI, D. Perspectiva marxiana do problema subjetividade - intersubjetividade. In: DUARTE, N.

Crítica ao fetichismo da individualidade. 2. ed. rev. Campinas: Autores Associados, 2012. p. 21-52.

\title{
THE EXPRESSION OF THE SINGULAR-PARTICULAR-UNIVERSAL DIALETICS WITHIN HISTORIC-CRITICAL PEDAGOGY: PRELIMINARY NOTES
}

\begin{abstract}
Preliminary approximations between the singular-particular-universal dialectics and the historical-critical pedagogical theory are elaborated in this paper, based on the exposition of the categories of singularity, universality and particularity articulated to the demands that the materialistic historical-dialectical method places as a condition for the production of knowledge capable of apprehending reality in its concreteness. It is argued that historical-critical pedagogy carries in its formulation the movement of these categories, formulating notes related to the concept of educational work, the problem of the curriculum and the subject towards which is directed the pedagogical act. Demonstrating that the categories of singular, particular and universal enable multiple analytical movements in the field of school education is one of the purposes of the analysis that is developed along the paper.
\end{abstract}

Keywords: critical-historical pedagogy; singular-particular-universal dialectics; knowledge production; educational labor.

\section{DIALÉTICA SINGULAR-PARTICULAR-UNIVERSAL Y SU EXPRESIÓN EN PEDAGOGÍA HISTÓRICO-CRÍTICA: APROXIMACIONES INICIALES}

\begin{abstract}
Resumen
Se realizan primeras aproximaciones entre la dialéctica singular-particular-universal y la teoría pedagógica histórico-crítica, a partir de una exposición de las categorías de singularidad, universalidad y particularidad articuladas a las exigencias que el método histórico-dialéctico materialista pone como condición para conocer la realidad en su concreción. Se argumenta que la pedagogía histórico-crítica lleva en su formulación el movimiento de estas categorías, formulando proposiciones relacionadas con el concepto de trabajo educativo, la problemática del currículum y el sujeto-receptor del acto pedagógico, intentando mostrar que las categorías de singular, particular y universal posibilitan múltiples movimientos analíticos en el campo de la educación escolar.
\end{abstract}

Keywords: pedagogía histórico-crítica; dialéctica singular-particular-universal; producción de conocimiento; trabajo educativo. 